\title{
Obituaries
}

\section{Dr Denis Murphy}

Formerly Consultant Forensic Psychiatrist at Lambeth Hospital (Ward in the Community and Hopton Road), South London and Maudsley NHS Foundation Trust, UK

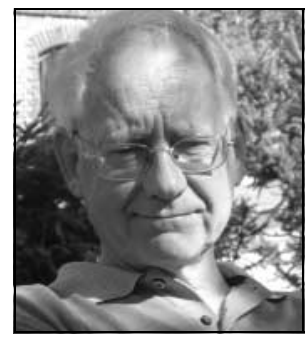

Denis Murphy, who died in 2010 aged 60 , was a man of strong convictions and broad interests who was intrigued by what made people tick, especially those most damaged and marginalised in society.

He was born in 1950 in Dublin, Ireland, the younger son of a neurologist. He was educated at first by the Jesuits and then at University College Medical School, Dublin. He began his career in psychiatry on the training programme in 1977 at St Guy's Hospital in London, UK. On completion of training he worked for 2 years as a Research Fellow in Psychopharmacology at Ann Arbor, Michigan, USA, beginning in 1981. He returned to London to the Institute of Psychiatry to specialise further in forensic psychiatry, including work at Broadmoor Hospital.

He was appointed consultant at the Special Assessment and Supervision Forensic Service, Cane Hill Hospital in 1989. Ten years later he joined the South London and Maudsley NHS Foundation Trust as consultant to the Forensic Rehabilitation Service based at Lambeth Hospital (Ward in the Community) and at Hopton Road where he remained until his death. Denis played a major role in the establishment and development of this innovative service, combining elements of individual and group psychotherapy treatments as well as therapeutic community approaches.

He had an abiding interest in psychoanalysis, and trained to become a member of the Institute of Group Analysis in 1997, followed by active membership of the International Association for Forensic Psychotherapy, and an MA in Clinical Psychoanalysis in 2003. He was in analytic treatment with Earl Hopper. This additional experience informed Denis' assessment and treatment skills with forensic patients, and also equipped him to work in group therapy at St Thomas' Hospital Psychotherapy Department and at Wandsworth Prison.

He was also active in the Doctors' Support Group, providing confidential assessment and psychological support to doctors in personal and professional relationship difficulties.

Denis produced several academic papers reflecting his wide interests in biological psychiatry, psychoanalytic understanding, group process and professional teamwork.

He was a devoted family man who loved socialising, talking, debating, walking, food, reading, rugby, gardening, cycling and tennis. He was both gregarious and introspective and remains a lasting inspiration and a deep loss. He is sorely missed by his patients, colleagues, friends and family, and is survived by his mother Kathleen, wife Eva, daughters Genny and Miranda, and stepsons Crispin and Sebastian.

Peter Hollis

doi: 10.1192/pb.bp.112.039115

\section{Professor Eadbhard O'Callaghan}

Formerly Newman Professor of Mental Health Research, University College Dublin and Consultant Psychiatrist, DETECT Early Intervention Service and Cluain Mhuire Family Centre, St John of God Hospital, Dublin, Ireland

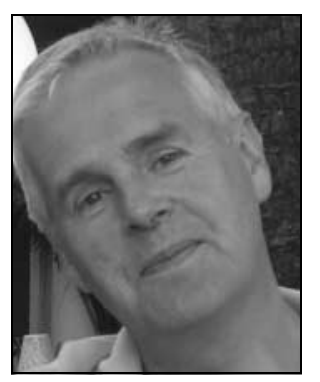

Eadbhard Dónal O'Callaghan, who died aged 53, was one of the earliest proponents of the neurodevelopmental model of schizophrenia identifying obstetric complications and influenza as key risk factors of the disease. He was intensely intellectual and had a passionate interest in sports - sometimes explaining complex scientific ideas in terms of tactics adopted by Liverpool Football Club. He was one of the foremost researchers in Irish psychiatry and a passionate advocate of early intervention in psychosis. He was an inspiring mentor to the cohort of Irish psychiatrists on whom he lavished attention during his time as tutor on the St John of God psychiatric training scheme. Many psychiatrists in academic positions in Ireland and elsewhere are indebted to Eadbhard for first recognising and encouraging their interest in research.

He was born in Dublin on 8 July 1957 and began his medical studies at the Royal College of Surgeons in Ireland in 1976. His medical school yearbook mentions his scientific mind and 'obsession for mastering the unknown' balanced by his sense of mischief and his 'charming smile'. On qualifying he specialised in psychiatry and joined the St John of God rotational training scheme. There it became clear that he had a rare talent for relating to people in trouble. Indeed, his insight, his judgement and the kindness he showed to his patients were remarkable.

On completing his membership examination he took up a post as Research Fellow in the St John of God services under the supervision of Conall Larkin and John Waddington. Eadbhard had a particular interest in psychotic disorders and in the 'new' neurodevelopmental theories of schizophrenia which were just coming to the fore at the time. Even though still a relatively junior researcher, he published highly cited papers on obstetric complications and minor physical anomalies as risk factors for schizophrenia, thus providing crucial support for the neurodevelopmental model. He was offered a fellowship with Professor Robin Murray at the Institute of Psychiatry, King's College London. The fellowship got off to a somewhat shaky start. The twin study that Eadbhard had originally come to work on did not go ahead and he had to find something else to do. He then persuaded Professor Murray that epidemiology was a promising approach. With colleagues Nori Takei and Pak Sham, Eadbhard published a seminal paper in the Lancet showing that prenatal influenza increases the risk for schizophrenia. This paper changed the direction of Professor Murray's research and his department soon became one of the main centres for epidemiological work in psychosis; due in 